\title{
A combined experimental and optimization model to improve the machinability of Nimonic C-263 superalloy
}

Prashant S. Jadhav, Chinmaya P. Mohanty*

School of Mechanical Engineering, VIT University, Vellore-632014, India

*Corresponding author. chinmaymohantymech@gmail.com

\begin{abstract}
Nickel based superalloys finds extensive usage in manufacturing of intricate part shapes in gas turbine, aircraft, submarine, and chemical industries owing their excellent mechanical property and heat resistant abilities. However, machining of such difficult-to-machine alloys up to the desired accuracy and preciseness is a complex task owing to a rapid tool wear and failure. In view of this, present work proposes an experimental investigation and optimization of process parameters of the cryogenic assisted turning process during machining of Nimonic $\mathrm{C}$ 263 super alloy with a multilayer CVD insert. Taguchi's L-27 orthogonal array is used plan the experiments. Effect of input parameters viz. cutting speed (N), cutting feed (f), depth of cut (d) are studied on responses viz. surface roughness (SR), nose wear (NW) and cutting forces (F) under hybrid cryogenic (direct+indirect) machining environment. A scanning electron microscope (SEM) analysis is carried out to explore the post-machining outcomes on the performance measures. The multiple responses are converted in to single response and ranked according to Taguchi based gray relational grade (TGRG). Feed rate (f) is found to be the most influential parameter from the analysis of variance of GRG. The means of GRG for each level of process parameters are used to improve the optimal process parameters further. Finally, the confirmative experiment is performed with these optimal set of process parameters which showed an improvement of $9.34 \%$ in the value of GRG. The proposed work can be beneficial to choose ideal process conditions to enhance the performance of turning operation.
\end{abstract}

Keywords: Nimonic C-263 alloy, surface roughness, Taguchi based Grey relational analysis 


\section{Introduction}

Now-a-day's Nickel alloys find a wide- ranging applications in the manufacturing of critical parts for aircraft, marine, automotive, gas turbine engines, nuclear plants owing to their capability to sustain the extreme temperature range and excellent mechanical property [1,2]. Machining of these superalloys precisely and accurately has become a complex task due to high hardness value and the cost associated with the machining of these alloys. In recent years, many superalloys viz. differe nt grades of Nickel, Titanium etc. having a unique set of properties have been developed for numerous engineering applications. Out of these many superalloys, Nimonic is a grade associated with Nickel based superalloy which can function at wide range of temperatures and have a lower value of creep. Normally, they comprise $45 \%$ Nickel, and $25 \%$ Chromium with a smaller percentage of cobalt, aluminium and titanium. The use of this superalloy is frequently seen in steam turbines and IC engines. Various grades of alloys on the basis of their composition like Nimonic 75, 80A, 90, 110, 105, 115, $263[3]$.

Nimonic C-263 is one of the important superalloy in this category which primarily contains Nickel and has a specific set of properties like high hot hardness, fatigue strength, creep resistance, better thermal stability at higher temperatures, high yield strength, high oxidation resistance and excellent ductility $[4,5]$. However, several difficulties are observed while machining the Nimonic C-263 alloy as it is low conductive at higher temperature and its tendency of work- hardening along with rough particle formation in its structure [6]. Additionally, due to precipitation hardening of cobalt within the structure improves the strength of the material and makes it harder to machine. Moreover, formation of built-up-edges (BUE) during machining of Nimonic C-263 deteriorates the surface integrity and leads to rapid tool failure.

In last few years, turning has been evolved to be an effective machining process and has engrossed interest of a lot of researchers. It is carried out varying several input parameters like spindle speed, cutting feed, depth of cut etc. Among the various responses, surface finishing and tool wear are the most important attributes to estimate the performance of the turning, as they directly govern surface characteristics viz. friction, wear, load carrying capacity on the machined parts. These attributes also largely affect the fatigue strength, surface integrity, dimensional accuracy and corrosion resistance which are basic requirements for the critical applications like aerospace parts. Therefore, it is vital task to optimize the machining parameters to achieve improved machining performance viz. lower surface roughness and flank wear for various combination of work piece and inserts.

Recently, numerous studies reported an application of cryogenic treatment to achieve improved machined surface quality and to reduce tool wear. In this aspect, some researchers have 
studied the effect of cryogenically treated inserts (indirect technique) with different soaking duration at different temperatures to achieve improved machined surface quality [7,24,26,29]. Similarly, few studies report impingement of cryogenic liquid on the machining zone (direct technique) can enhance the performance of the process [8-10]. However, report to analyze the machinability of process with the hybrid technique i.e. combination of both direct and indirect cryogenic approach is extremely scarce in the literature. Combination of both the beneficial techniques may further enhance the performance of turning operation. Thus, the novelty and prime motive of this study is to investigate the machinability of Nimonic C-263 work piece under a hybrid cryogenic machining approach i.e. machining with cryogenically treated inserts under cryogenic environment. Effect of machining parameters viz. cutting speed $(\mathrm{N})$, cutting feed (f), depth of cut (d) are explored on responses viz. surface roughness $(\mathrm{SR})$, nose wear $(\mathrm{NW})$ and cutting forces $(\mathrm{F})$ under the hybrid machining environment.

Taguchi-based grey relational analysis (TGRA) is amongst the simplest and systematic technique for dealing with multi-objective problems and several researchers have already attempted this to their machining study conducted at various environments $[34,36,39,41]$. However, the available literature of TGRA lacks applicability of this method to combined direct and indirect cryogenic approach and hence, TGRA method is adopted to rank the responses in the present study. The optimum machining condition obtained through the approach is validated by conducting a confirmative test.

Complex shapes can be machined to desired dimensional accuracy with turning process. There are various factors in the turning which influences the performance measures viz. surface roughness, tool wear, cutting force etc. In a case of cutting insert, parameters like nose radius, rake angle, tool point angle, tool materials, etc. are significant whereas, for the workpiece, material properties, hardness and cutting conditions are significant [11,12]. To enhance the performance of turning process, numerous studies have been reported by researchers are discussed in this section. Rotational turning and hard turning have been compared with respect to the surface quality and there were no significant differences observed between the two techniques however, rotational turning showed improved results in terms of wear of tool, while hard turning performed better with respect to the surface integrity [13-15]. Therefore, the hard turning is more often used. Batish et al. explored the surface topography and concluded that machining forces depend upon various factors like cutting speed, feed rate and depth of cut whereas surface roughness largely depends upon the feed rate [11]. Different features of surface integrity for AISI D2 steel that has been coated with carbide inserts have 
been compared by Srithar et al. and Thakur et al. in their studies $[12,16]$. It is observed that there is a reduction in the surface integrity as spindle speed and the feed rate increases. However, surface roughness is mostly influenced by the speed and least affected by the depth of cut $[14,17]$. Thakur et al. has explored the tool wear, surface integrity and the tool life by comparing with taper turning [18].

In recent years, numerous studies reported application of nickel-based superalloys which finds extensive applications in manufacturing critical parts used in aerospace, defense and nuclear industries etc. Out of many superalloys, Nimonic C-263 is amongst the difficult to machine superalloy due to its inherent characteristics like lower thermal conductivity, large strain rate sensitivity, greater chemical affinity, and higher range of hot hardness [7]. These features of Nimonic alloys results into high friction and generation of excess heat at machining zone. In this aspect, Ezilarasan et al. have machined Nimonic C-263 superalloy and analyzed various responses viz; cutting force, surface roughness, tool wear rate [5]. The same researcher also used whisker-reinforced ceramic insert in other study where he observed higher range of residual stresses with whiskerreinforced ceramic inserts [19]. Koyilada et al. have analyzed the performance of CVD versus PVD coated tool while turning Nimonic alloy and studied various responses viz. tool wear, cutting force, cutting temperature [20]. The study revealed that the PVD coated tool successfully controls the tool wear for the complete range of spindle speed. Few researchers have used TiN/TiCN/A12O3/ZrCN CVD coated inserts for the turning the Nimonic alloy and studied responses like chip reduction coefficient $(\zeta)$, cutting temperature etc. Flank wear, fracturing of nose are the limiting factors occurring due to abrasion wear, diffusion wear, fatigue loading during hard turning which ultimately affects the tool life adversely. Hence, to improve tool life, suitable choice of material selection is important [16,21]. The cutting tools must have the properties viz. good balance of hardness and toughness, anti-friction and chemical inertness properties, excellent thermal stability along with hot hardness. In order to achieve the above features, various kind of coated and uncoated material have been used in both multilayer and single layer configuration by earlier researchers. Furthermore, CVD coated tool established great features during the machining of various types of Nickel based superalloys [22,23].

Numerous machining approaches have been implemented by various researchers for improving the efficiency of the turning process. Use of lubricants and coolants on the tool-workpiece interaction zone reduces the cutting temperature considerably. To achieve effective lubrication and cooling, several methods have been employed. Lubricant which are commonly used in various industries are water based soluble oils or mineral oils. These oils are ecological threat as they have 
many harmful effects on workers' health. To overcome these harmful impacts, a sustainable machining strategy such as cryogenic machining (direct cryogenics) have been claimed by researchers [24,25,29] who examined the effects of machining environment like high pressure cooling and direct cryogenic cooling on the life of tool and surface integrity throughout the machining of workpiece. The experimental results have shown that the suggested higher-press ure cooling approach carried significant growth of tool life of $133 \%$ for PVD double layered coated tool and microcrystalline uncoated carbide inserts have maximum of 275\%. Apart from this, few researchers presented the report on cryogenic treatment of inserts i.e. indirect cryogenics to achieve better tool life [26-28]. Chetan et al. is the only researcher who has carried out turning process on Nimonic work piece with cryo-treated inserts till date [29]. However, tool wear has not been considered as a response in the study. Few studies also claimed that the lowering temperature can enhance the performance of the turning process on the machined surface keeping soaking duration constant $[30,31]$.

In addition to these studies, several researchers have also opted for application of various optimization techniques to achieve optimum level of machining condition for turning process [5] in which they have presented a multiple objective optimization of the cutting features by considering desirability functionality towards obtaining the lower values of the mentioned responses and obtained the optimum parametric combination with feed rate of $0.05 \mathrm{~mm} / \mathrm{rev}$, cutting-speed of $210 \mathrm{~m} / \mathrm{min}$ and a depth of $0.5 \mathrm{~mm}$ to optimize the multi-objective turning problems effectively in combination with a desirable accuracy. Few researchers carried out an optimization with genetic algorithm for the turning process to get the optimum set of machining parameters [11,15]. Neseli et al. implemented the response surface methodology and optimized various cutting tool geometry attributes [32]. Grey relational analysis was carried out for optimizing input parameters to minimize the values of residual stresses and surface roughness [33].

Extensive study of past literature indicates that good amount of work has been reported worldwide to enhance the performance of turning process by the researchers. Literature reports abundant works on indirect cryogenic and direct cryogenics approaches to achieve improve machinability on various combination of work-tool pair individually [24-29]. However, to the best of our knowledge, a report that evaluates the machinability of the turning process combining the hybrid strategy of both direct and indirect is extremely scarce in the literature. Moreover, it is also observed that limited number of studies have explored the machinability of Nimonic 263 work piece in turning process. This superalloy finds abundant usage in manufacturing complex parts in gas 
turbine, aerospace and automotive industries. Therefore, attempt must be made to explore the machinability of Nimonic C 263 work piece in the hybrid cryogenic machining environment. Therefore, the proposed work attempts to evaluate the combined effect of hybrid cryogenic machining strategy i.e. combination of direct and indirect cryogenic machining on Nimonic C263 work piece. Taguchi based gray relational grade (TGRA) is used to convert multiple responses viz. surface roughness, cutting forces and tool wear in to equivalent gray relational grade (GRG). The GRG is further optimized and validated by conducting a confirmation test.

\section{Experimental design and procedure}

For the experiment, cutting speed(N), cutting feed (f) and depth of cut (d) are selected as the important machining parameters whereas surface roughness, nose wear and cutting forces are considered as important performance measures in this study. Workpiece material selected is Nimonic C-263 bars of diameter $25 \mathrm{~mm}$ and length $125 \mathrm{~mm}$. The mechanical properties of Nimonic C-263 are as shown in the Table 1.

[Table 1 about here.]

The tool insert material used for turning was T-style tool insert with multilayer CVD coating of TiN-MT-TiCN- $\mathrm{Al}_{2} \mathrm{O}_{3}$ grade KCM25. Each hard turning experiment was performed twice and mean of the result is considered for better accuracy. Figure 1 shows the pictorial view of hybrid cryogenic experimental setup (direct+indirect) and details of the experimentation are given in the Table 2 along with the level of parameters selected.

[Fig. 1 about here.]

Taguchi's robust L27 orthogonal array is used to plan the experiments with an objective of extracting maximum information from the study with minimum experimental runs. Decision of experiments (DOE) and the performance analysis is done via Minitab18 statistical software. The relation between objective value and functional value is identified and emphasized as Taguchi loss function. It is mathematically written as shown in Equation 1,

$$
\mathrm{L}(\mathrm{y})=\frac{\mathrm{L}(\mathrm{m})(\mathrm{y}-\mathrm{m})^{2}}{2}=\mathrm{k}(\mathrm{y}-\mathrm{m})^{2}=\mathrm{k}(\sigma)
$$

Here, the term y represents the value of the quality characteristic,

$\mathrm{k}$ denotes the proportionality constant ; $\mathrm{L}(\mathrm{y})$ denotes the loss function.

$\mathrm{m}$ denotes the target value of $\mathrm{y} ; \quad \sigma$ represents a mean square deviation.

[Table 2 about here.] 


\subsection{Cryogenic treatment on inserts}

Cryogenic treatment is an indirect cryogenic method which comprises the process of treating the inserts at sub-zero condition (below $0^{\circ} \mathrm{C}$ ) to enhance their mechanical properties. For this method, various gases such as $\mathrm{CO}_{2}$, liquid nitrogen and helium are generally used as working medium. In this study, cryogenic treatment on the tool inserts was done to find out its effect on the response parameters along with direct cryogenics. Liquid nitrogen was used as working medium $\left(\mathrm{LN}_{2}\right)$ for this study and cryogenic temperature selected was $-100^{\circ} \mathrm{C}$ along with soaking duration of 12 hours. Cooling rate was throughout kept constant as $2^{\circ} \mathrm{C} / \mathrm{min}$. After this sub-zero treatment, tempering was carried out at $200^{\circ} \mathrm{C}$ on the samples to eliminate the internal residual stresses with same rate of $2^{\circ} \mathrm{C} / \mathrm{min}$ and held at that temperature for 2 hours. The inserts were then cooled down in the air slowly. The optimal specifications for cryogenic treatment were selected by referring previous literatures [26-28]. Figure 2 shows the timeline of the various heat treatment processes.

[Fig. 2 about here.]

The cryogenic treatment improves the micro hardness values of carbide inserts. This has also been supported by few previous studies. This is primarily due to the fact that with cryogenic treatment, there is formation of eta precipitates. XRD analys is of the untreated and treated inserts is carried out to validate this eta formation and results are shown in the figure 3 . The presence of tiny sharp peaks post to the cryogenic treatment observed in the XRD profile implies the formation of complex compound carbide phases. Moreover, grain refinement at lower temperature is another reason for this improvement in the hardness values of cryo-treated insert.

[Fig. 3 about here.]

To validate this, a full width at half maxima (FWHM) received from XRD pattern is studied. FWHM corresponds to the enlargement of peaks which further are associated with the grain refinement. Figure 4 reveals the distinction of FWHM for untreated and treated inserts corresponding to the diffraction angle. FWHM value can be seen larger in case of cryo-treated inserts as compared to the untreated inserts. Larger FWHM value in carbide insert implies to the additional refinement of grains that resulted into an increased value of hardness. This is also supported by previous researches in which they also claimed that the refinement of grains occurred through the cryogenic treatment increases the hardness and wear resistance of tungsten carbide inserts [14,28,34].

[Fig. 4 about here.] 


\subsection{Cryogenic machining environment}

This is also known as a direct method of cryogenics where the jet of $\mathrm{CO}_{2}, \mathrm{LN}_{2}$ is projected directly over the cutting zone. Many researchers have achieved increase in tool life with the help of cryogenic cooling. This method removes heat from cutting zone and at the same time, it also reduces the coefficient of friction by providing cushioning effect between chip-tool interface. Liquid nitrogen at $-196^{\circ} \mathrm{C}$ has commonly been used as a coolant in the cryogenic machining. Liquid nitrogen is an inert gas and also it is not dangerous to the workers on the shop floor. Also, it minimizes the diffusion wear and adhesion performance of cutting tool henceforth increases the tool life. Figure 5 is the block diagram of the machining setup prepared for the same.

[Fig. 5 about here.]

\section{Measurement of responses}

\subsection{Surface roughness measurement}

The surface roughness (SR) testing carried out with the help of Taylor Hobson Talysurf surface roughness tester (Mitutoyo made) as shown in Figure 6. The workpiece was rotated randomly and 4 readings were taken at $90^{\circ}$ angle each. The average of these readings ( $\mathrm{R}_{\mathrm{a}}$ in microns) was taken as the final value of surface roughness.

[Fig. 6 about here.]

\subsection{Tool wear measurement}

The nose wear (NW) was carried out using Toolmakers' microscope (Mitutoyo made) shown in Figure 7. The tool insert is placed on the glass below the lens of $10 \mathrm{X}$ magnification power. All the readings were taken twice and average is taken for better accuracy. The readings are expressed in millimetre.

[Fig. 7 about here.]

\subsection{Cutting force measurement}

The cutting force (CF) was measured using lathe tool dynamometer 5233A (Kistler made). The data procurement system comproses of software DynoWare software. This cutting force is the resultant of the tangential force and the feed force and expressed in newton $(\mathrm{N})$. The Figure 8 shows the data acquisition system for cutting forces from DynoWare software.

[Fig. 8 about here.] 


\section{Results and discussion}

Table 3 shows the Taguchi's L-27 orthogonal array of twenty seven experimental runs along with the responses viz; surface roughness (SR), nose wear (NW) and cutting forces (CF). It also shows the results of turning operation viz; surface roughness, cutting forces and nose wear. Moreover, it also comprises Grey relational coefficients (GRC), Grey relational grade (GRG) and rank after Taguchi based grey relational analys is operations.

[Table 3 about here.]

\subsection{Analysis of surface roughness}

Surface roughness is one of the crucial response in hard turning process as it influences the tool wear and tribological properties of machined surface. The effect of different input variables viz; spindle speed, feed and depth of cut are studied individually on responses like surface roughness, nose wear and cutting forces in this section. Figure 9 shows the main effect plot values for surface roughness measured at different levels of cutting speed $(50,80,110 \mathrm{~m} / \mathrm{min})$, depth of cut $(0.4,0.6,0.8 \mathrm{~mm})$, feed rate $(0.08,0.1,0.12 \mathrm{~mm} / \mathrm{rev})$.

[Fig. 9 about here.]

From the main effect plot, it is observed that, the value of surface roughness has been reduced with increasing speed. Figure also shows the incremental trend in the values of surface roughness with an increasing cutting feed values. This is due to the fact that the cutting load increases over the tool with increasing feed rate that leads to excess frequency of vibrations of tool resulting into poor surface finish. The best surface finish is obtained at the lowest cutting feed and highest spindle speed combination. Figure also shows that if the depth of cut is increased, surface finish obtained is very poor. This is due to the excessive rubbing action and temperature rise with an increasing depth of cut that causes increase in surface roughness value.

\subsection{Analysis of tool wear}

Tool wear is also the most crucial response as it affects the dimensional exactness and surface integrity of the machined component. It is also an important aspect which decides the tool life which ultimately is associated with the cost of machining. In machining, the nose wear is responsible for the cutting-edge retreat and has a greater influence on the dimensional accuracy of a workpiece. Figure 10 shows the main effect plots for the nose wear obtained below the ISO 3658-1993 standards.

[Fig. 10 about here.] 
For the spindle speed of $110 \mathrm{~m} / \mathrm{min}$, the value of the tool wear is least till $0.122 \mu \mathrm{m}$. Further, it is also evident from the graphs that, at $110 \mathrm{~m} / \mathrm{min}$ of spindle speed, the tool wear is reduced approximately by $25 \%$ as compared to the lower speed of $50 \mathrm{~m} / \mathrm{min}$.

\subsection{Analysis of cutting forces}

Cutting force generation influence the stability of a machining system. it may deform the workpiece with non-uniform chip formation and dimensional accuracy may be lost. Figure 11 shows the main effect plots for cutting forces which shows that at the higher cutting feed and lower spindle speed, the cutting force generation is on the peak.

[Fig. 11 about here.]

The extreme high value of cutting forces measured was approximately $223 \mathrm{~N}$ for the spindle speed of $50 \mathrm{~m} / \mathrm{min}, 0.12 \mathrm{~mm} / \mathrm{rev}$ of feed and $0.8 \mathrm{~mm}$ of depth of cut whereas, the lowest cutting force was observed at the maximum speed of $110 \mathrm{~m} / \mathrm{min}$, minimum feed rate of $0.08 \mathrm{~mm} / \mathrm{rev}$ and lowest depth of cut of $0.4 \mathrm{~mm}$. This is because at lower cutting speeds, residual stresses formed in the workpiece are of tensile in nature and if the depth of these stresses are increased then cutting force generated at the zone is higher. A similar observation has been reported by Tugrul Ozel et al. in their research [35].

\section{Grey Relational Analysis}

Taguchi based Grey relational analysis (TGRA) is familiar for treating problems having interfunctional relationship among multiple input parameters and response variables. Multiple input parameters considered in this study are the cutting parameters are cutting speed $(\mathrm{N})$, feed rate $(\mathrm{F})$, depth of cut (D). Tables 3 shows the level of input parameters and the associated readings considered for multi- optimization. Twenty-seven different sets of experiments are carried out in this study which are further optimized using Taguchi based Grey relational analysis. The responses considered during this study are namely surface roughness, nose wear and cutting forces. These machining performances were transformed to the single common dataset by estimating Grey Relational Grade (GRG) [36]

\section{a) Data set normalization}

As the motive is to estimate an optimum range of input variables yielding minimal values of surface roughness, nose wear and cutting forces, lower-is-better model is implemented as per Equation (2). Normalized value $\mathrm{Xi}(\mathrm{j})$ of $\mathrm{Xi}(\mathrm{j})$ is obtained by equation (2) 


$$
X i *(j)=\frac{\max j . X i(j)-X i(j)}{\max j . X i(j)-\min j . X i(j)}
$$

Where, max $\mathrm{j} . \mathrm{Xi}(\mathrm{j})$ is the highest $\mathrm{j}$ value and $\min \mathrm{j} . \mathrm{Xi}(\mathrm{j})$ is the lowest $\mathrm{j}$ value.

\section{b) Estimating grey relational coefficient (GRC)}

Grey relational coefficient is $\mathrm{Yoi}(\mathrm{j})$ is estimated by using equation (3)

$$
\text { ? } 0 \mathrm{i}(\mathrm{j})=\frac{\Delta \min +£ \Delta \max }{\Delta 0 \mathrm{i}(\mathrm{j})+£ \Delta \max }
$$

where $\Delta 0 \mathrm{i}(\mathrm{j})=\mathrm{X} 0 *(\mathrm{j})-\mathrm{Xi} *(\mathrm{j})$ is the trend showing deviation for $\Delta 0 \mathrm{i}(\mathrm{j}), \Delta \max =\operatorname{maximaxj} \Delta 0 \mathrm{i}(\mathrm{j})$, $\Delta \min =\min \mathrm{i} \cdot \min \mathrm{j} \Delta 0 \mathrm{i}(\mathrm{j})$ and $£$ is distinguishing factor, $£ \varepsilon[0,1]$

c) Estimation of grey relational grade (GRG)

After GRC, Grey relational grade can be estimated by equation (4)

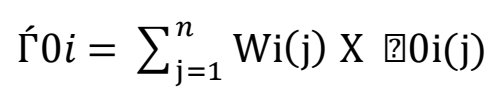

\section{d) Assigning the Rank to a data}

The highest value of GRG is assumed to be the most influential combination and are assigned with rank accordingly. GRG was estimated for all set of data values and it is used to identify the most significant levels of input parameters at which improved results are obtained. Table 3 shows GRC, GRG and rank for the experimental values whereas. Table 4 shows mean of GRG values for each level. The larger GRG value implies the degree of closeness of experimental response to the ideal value. From the Table 4, it is observed that second experimental combination shows the largest amonst all the 27 experiments. The GRG value is further analysed by using ANOVA to analyse the influence of individual parameter on the value of grey relation grade.

[Table 4 about here.]

\section{Analysis of variance}

The motive of ANOVA is to find out the most significant machining parameters that influe nces machining process. It provides the data such as degrees of freedom, sum of squares, mean squares, Fvalue, P-value and \% contribution of parameters. Table 5 illus trates the ANOVA results which clearly shows that a cutting feed is the most significant attribute in cryogenic hard turning of Nimonic C-263 superalloy that contributes $48.33 \%$. Past research also found the same trend of results [37]. It can also be seen that the spindle speed has $14.90 \%$ contribution whereas, depth of cut has $36.77 \%$ contribution on the performance of hard turning. 
[Table 5 about here.]

\section{Confirmation experiments}

The trial experiments were conducted as a confirmation test considering optimum combination of machining parameters to validate the TGRA. The predicted Grey relational grade projected is estimated using equation (5).

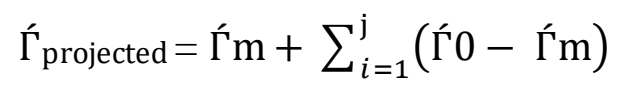

Where, Ím implies the mean of total GRG

Ѓ 0 implies average of the optimal levels GRG

$\mathrm{j}$ is total no. of the input parameters.

The predicted GRG for optimum parameters is computed from equation (5) and were tabulated in the Table 6. Experimental trial carried out as confirmation test and their results were compared with the values of first ranked set i.e. $2^{\text {nd }}$ orthogonal array. Table 6 confirms that there is reduction in cutting force from $188.3 \mathrm{~N}$ to $161.14 \mathrm{~N}$, surface roughness reduction from $0.911 \mu \mathrm{m}$ to $0.837 \mu \mathrm{m}$, tool nose wear reduced from $0.07 \mathrm{~mm}$ to $0.06 \mathrm{~mm}$ and GRG improved by $9.34 \%$. These results are also supported by previous studies [34,36,38]. Hence, above results show that there is considerable improvement observed in the machining performance during extremely difficult to machine Nimonic C-263 material with the Taguchi based grey relational analysis.

[Table 6 about here.]

After selection of the optimum machining parameters, $14.42 \%$ reduction was observed in the cutting forces in comparision to the machining parameters of $2^{\text {nd }}$ orthogonal array. This is due to the fact that the excessive temperature generated at higher spindle speeds caused thermal softening of the workpiece, moreover, the $\mathrm{LN}_{2}$ over machining zone exhibited the cushioning effect. This resulted into the reduced machining zone friction which ultimately decreased the tool-tip shearing area. At the selected optimum machining parameters, surface finish was observed to be improved by $8 \%$ compared to the $2^{\text {nd }}$ orthogonal array. Figure 12 shows the scanning electron microscope (SEM) morpholoies of machined surface in which $2^{\text {nd }}$ orthogonal array image is shown in fig 12(a) whereas, image obtained with optimal process parameters is illustrated in fig 12 (b). This clearly shows the micro cavities on the surface for $2^{\text {nd }}$ orthogonal array. On other hand, optimal machining parameters show comparatively better surface morphology. This is primarily due to the fact that the region in the vicinity of chip-tool interface is thermally softened at higher temperatures which leads into the minimization of surface 
flaws and discontinuities at the machining zone. This is also supported by the previous researchers $[39,40]$.

[Fig. 12 about here.]

Figure 13 (a) and 13 (b) shows the SEM images of the tool morphology after machining with $2^{\text {nd }}$ orthogonal array and optimised machining parameters respectively. Rapid tool wear is observed at the morphology obtained with $2^{\text {nd }}$ orthogonal array machining parameters. The reason of this tool wear is primarily due to the abrasion and weakening of the section. On other hand, less damage is observed in the morphology obtained with optimal machining parameters.

[Fig. 13 about here.]

\section{Conclusions}

The combined use of direct and indirect cryogenics implemetation along with multi-objective optimization of machining parameters for turning of Nimonic C-263 superalloy have been presented in this work. The cryogenic machining strategy has proven to be an environment friendly and work friendly machining approach as it doesn't have any ecological hazards. Moreover, there is no concern of leakage of coolant waste, as $\mathrm{LN}_{2}$ is disperesed in an atmosphere immediately after contact with a machining zone. It has also been found that with use of $\mathrm{LN}_{2}$ as a coolant, there is no attempt required for disposal of the same. The key findings obtained from the study are discused below.

- Taguchi based grey relational analysis is amongst the simplest technique to treat multi response optimisation problems and involves least computation steps.

- The ideal combination for cryogenic hard-turning machining attributes obtained as spindle speed of $110 \mathrm{~m} / \mathrm{min}$, cutting feed of $0.08 \mathrm{~mm} / \mathrm{rev}$ and depth of cut as $0.4 \mathrm{~mm}$.

- Feed rate has found to be the most crucial parameter which influences the hard turning upto $48.33 \%$.

- On machining the Nimonic C 263 workpiece again with optimum combination of process parameters obtained from TGRA, cutting force found to be decreased from $188.3 \mathrm{~N}$ to 161.14 $\mathrm{N}$, surface roughness reduced from $0.911 \mu \mathrm{m}$ to $0.837 \mu \mathrm{m}$ whereas, tool nose wear reduced from $0.07 \mathrm{~mm}$ to $0.06 \mathrm{~mm}$.

- The values obtained from TGRA are again validated by carrying out a confirmative test predicting an improvement of $9.34 \%$ in between the experimental and otimization results. 


\section{References}

[1] Ezugwu, E.O., Wang, Z.M., \& Machado, A.R. (1999). The machinability of nickel- based alloys: a review. Journal of Materials Processing Technology, 86(1-3):1-16.

[2] Özgün,Ö. Gülsoy,H.Ö.,Findik F,\&Yilmaz, R.(2012).Microstructure and mechanical properties of injection moulded Nimonic-90 superalloy parts. Powder Metallurgy, 55(5):405- 414.

[3] Patel, S.J. (2006). A century of discoveries, inventors, and new nickel alloys. The Journal of The Minerals, Metals \& Materials Society, 58(9):18-20.

[4] Podder, B. \& Paul, S. (2012). Improvement of machinability in end milling of Ni- monic C263 by application of high-pressure coolant. International Journal of Machining and Machinability of Materials, 11(4):418-418.

[5] Ezilarasan, C., Kumar, V.S., Velayudham, A., \& Palanikumar, K. (2011). Surface roughness analysis on machining of Nimonic C-263 alloy using ANN and RSM techniques. International Journal of Precision Technology, 2(4):340-340.

[6] Ezilarasan, C., kumar, V.S.S., \& Velayud- ham, A. (2014). Theoretical predictions and experimental validations on machining the Nimonic C-263 superalloy.

[7] Behera, B.C., Alemayehu, H., Ghosh, S., \& Rao, P.V. (2017). A comparative study of recent lubricoolant strategies for turning of Ni-based superalloy. Journal of Manufacturing Processes, 30, 541-552.

[8] Saini, S., Ahuja, I.S., \& Sharma, V.S. (2012). Influence of cutting parameters on tool wear and surface roughness in hard turning of AISI H11 tool steel using ceramic tools. International Journal of Precision Engineering and Manufacturing, 13(8):1295-1302.

[9] Aslantas,K.,Ucun,I', \& Çicek, A. (2012). Tool life and wear mechanism of coated and uncoated A12O3/TiCN mixed ceramic tools in turning hard alloy steel. Wear, 274:442- 451.

[10] Dogra, M., Sharma, V.S., Sachdeva, A., Suri, N.M., \& Dureja, J.S. (2010). Tool wear, chip formation and workpiece surface issues in $\mathrm{CBN}$ hard turning: A review. International Journal of Precision Engineering and Manufacturing, 11(2):341-358.

[11] Batish, A., Bhattacharya, A., Kaur, M., \& Cheema, M.S. (2014). Hard turning: Parametric optimization using genetic algorithm for rough/finish machining and study of surface morphology. Journal of Mechanical Science and Technology, 28(5):1629- 1640.

[12] Srithar, A., Palanikumar, K., \& Dur- gaprasad, B. (2014). Experimental Investigation and Surface roughness Analysis on Hard turning of AISI D2 Steel using Coated Carbide Insert. Procedia Engineering, 97:72-77.

[13] Degen, F., Klocke, F., Bergs, T., \& Ganser,P. (2014). Comparison of rotational turning and 
hard turning regarding surface generation. Production Engineering, 8(3):309- 317.

[14] Antonialli, A.I.S., Magri, A., \& Diniz, A.E. (2016). Tool life and tool wear in taper turning of a nickel-based superalloy. The International Journal of Advanced Manufacturing Technology, 87(5-8):2023-2032.

[15] Tebaldo, V., di Confiengo, G.G., \& Faga,M.G. (2017). Sustainability in machining: 'Ecofriendly" turning of Inconel 718. Surface characterization and economic analysis. Journal of Cleaner Production, 140:1567-1577. [16] Thakur A, Gangopadhyay S and Maity K P 2014 Procedia CIRP 14 541-545

[17] Thakur, A., Gangopadhyay, S., \& Maity,K.P. (2014a). Effect of cutting speed and CVD multilayer coating on machinability of Inconel 825. Surface Engineering, 30(7):516-523.

[18] Thakur, A., Gangopadhyay, S., \& Maity, K.P. (2014b). Effect of Cutting Speed and Tool Coating on Machined Surface Integrity of Ni-based Superalloy. Procedia CIRP,14:541-545.

[19] Ezilarasan, C., kumar, V.S.S., \& Velayud- ham, A. (2013a). An experimental analysis and measurement of process performances in machining of Nimonic C-263 superalloy. Measurement, 46(1):185-199.

[20] Koyilada, B., Gangopadhyay, S., \& Thakur, A. (2016). Comparative evaluation of machinability characteristics of Ni- monic C-263 using CVD and PVD coated tools. Measurement, 85(1):152-163.

[21] Dennison, M.S. \& Sivaram, N.M. (2017). The effectiveness of various cutting fluids on the surface roughness of AISI 1045 steel during turning operation using MQL system. Journal of Future Engineering Technology, 13(1):36-40.

[22] Ezilarasan, C., kumar, V.S.S., \& Velayud- ham, A. (2013b). Effect of Machining Parameters on Surface Integrity in Machining Nimonic C-263 Superalloy Using Whisker-Reinforced Ceramic Insert. Journal of Materials Engineering and Performance, 22(6):1619- 1628.

[23] Gupta, M.K., Sood, P.K., Singh, G., \& Sharma, V. (2017). Sustainable machining of aerospace material $\mathrm{Ti}$ (grade-2) alloy: Modeling and optimization. Journal of Cleaner Production, 147(2):614-641.

[24] SreeramaReddy, T.V., Sornakumar, T., VenkataramaReddy, M., \& Venkatram,R. (2009). Machinability of C45 steel with deep cryogenic treated tungsten carbide cutting tool inserts. International Journal of Refractory Metals and Hard Materials, 27(1):181-185.

[25] Podder, B. \& Paul, S. (2008). Effect of machining environment on machinability of Nimonic 263 during end milling with un- coated carbide tool. International Journal of Machining and Machinability of Materials, 3(1/2):104-104. 
[26] Chetan, Behera, B.C., Ghosh, S., \& Rao, P.V. (2016a). Wear behavior of PVD TiN coated carbide inserts during machining of Nimonic 90 and Ti6Al4V superalloys under dry and MQL conditions. Ceramics International, 42(13):14873-14885.

[27] Pusavec, F., Krajnik, P., \& Kopac, J. (2010). Transitioning to sustainable production - Part I: application on machining technologies. Journal of Cleaner Production, 18(2):174-184.

[28] Gill, S.S. (2012). Machining Performance of Cryogenically Treated AISI M2 HSS Tools. J. Eng. Stud, 3:1-5.

[29] Chetan, Ghosh, S., \& Rao, P.V. (2016b). Environment Friendly Machining of Ni-Cr-Co Based Superalloy using Different Sustainable Techniques. Materials and Manufacturing Processes, 31(7): 852-859.

[30] Dhananchezian, M. \& Kumar, M.P. (2011). Cryo-genic turning of the Ti-6Al-4V alloy with modified cutting tool inserts. Cryogenics, 51(1):34-40.

[31] Choudhury, I.A. \& El-Baradie, M.A. (1998). Machinability of nickel-base superalloys: a general review. Journal of Mate- rials Processing Technology, 77(1-3):278- 284.

[32] Neşeli, S., Yaldı, S., \& Türkeş, E. (2011). Optimization of tool geometry parameters for turning operations based on the response surface methodology. Measurement, 44(3): 580-587.

[33] Sarnobat, S.S. \& Raval, H.K. (2019). Experimental investigation and analysis of the influence of tool edge geometry and work piece hardness on surface residual stresses, surface roughness and work-hardening in hard turning of AISI D2 steel. Measurement, 131:235-260.

[34] Ranganathan, S. \& Senthilvelan, T. (2011). Multi-response optimization of machining parameters in hot turning using grey analysis. The International Journal of Advanced Manufacturing Technology, 56(5-8):455-462.

[35] Özel, T., Hsu, T. K., \& Zeren, E. (2005). Effects of cutting-ed ge geometry, workpiece hardness, feed rate and cutting speed on surface roughness and forces in finish turning of hardened AISI H13 steel. The International Journal of Advanced Manufacturing Technology, 25(3-4), 262-269.

[36] Tang, L., Du, Y.T., Tang, L., \& Du, Y.T. (2014). Multi-objective optimization of green electrical discharge machining Ti-6Al-4V in tap water via Grey- Taguchi method multiobjective optimization of green electrical discharge machining Ti-6Al-4V in tap water via Grey-Taguchi method. Materials and Manufacturing Processes, 29(5):507-513.

[37] Goel, B., Singh, S. and Sarepaka, R.V. (2015) 'Optimizing single point diamond turning for mono-crystalline germanium using grey relational analysis', Materials and Manufacturing Processes, 30(8) : 1018-1025 
[38] Senthilkumar, N., Tamizharasan, T., \& Anandakrishnan, V. (2014). Experimental investigation and performance analysis of cemented carbide inserts of different geometries using Taguchi based grey relational analysis. Measurement, 58:520-536.

[39] Sivaiah, P., \& Chakradhar, D. (2017). Multi-objective optimization of cryogenic turning process using Taguchi-based grey relational analysis. International Journal of Machining and Machinability of Materials, 19(4), 297-312.

[40] Pawade, R.S., Joshi, S.S., Brahmankar, P.K.\& Rahman, M. (2007). An investigation of cutting forces and surface damage in high-speed turning of Inconel 718. Journal of Materials Processing Technology,192:139-146.

[41] Lin, C.L. (2004). Use of the Taguchi method and grey relational analys is to optimize turning operations with multiple performance characteristics. Materials and Manufacturing Processes, 19(2):209-220. 


\section{List of Figures}

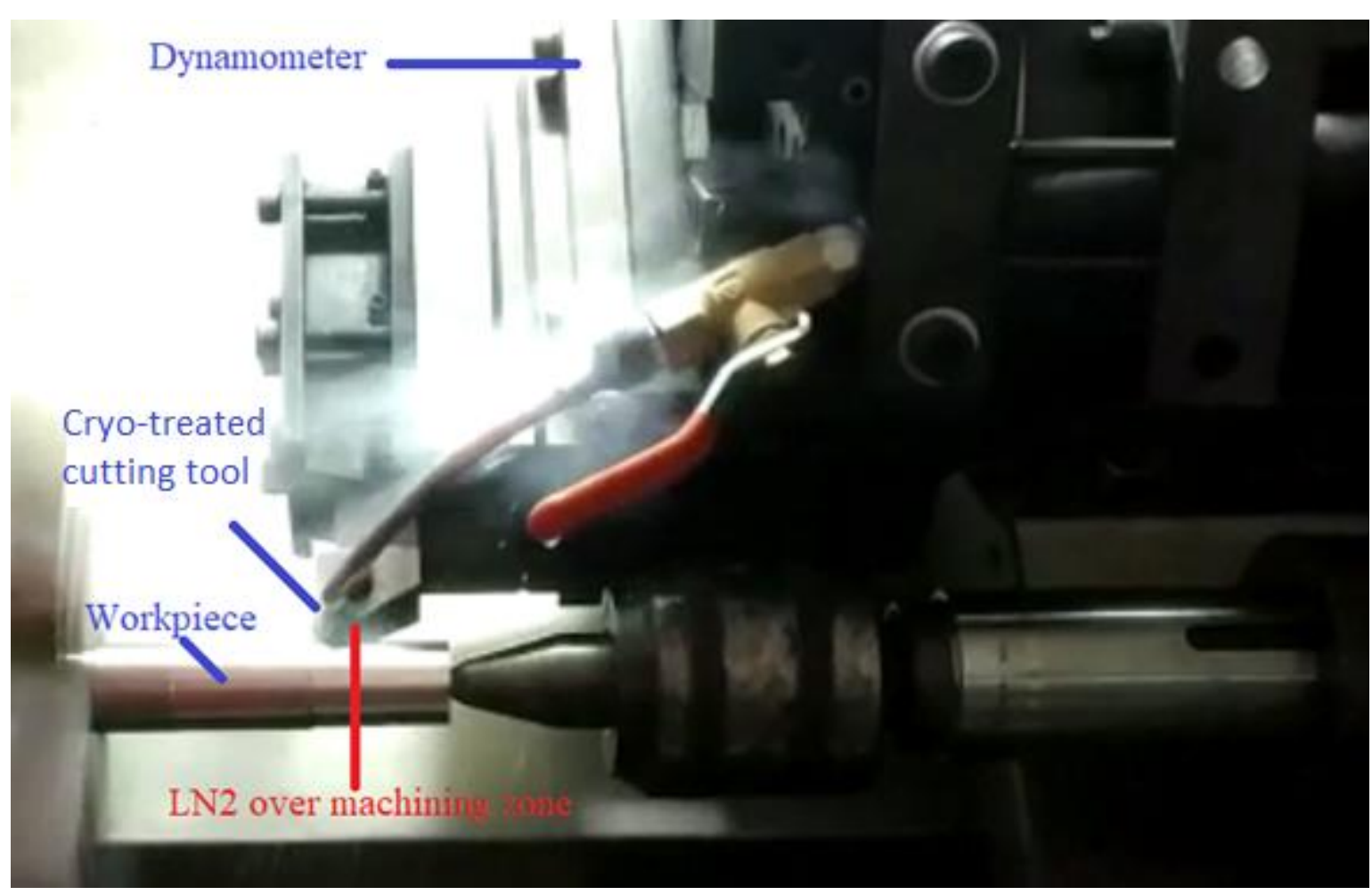

Fig. 1. Hybrid cryogenic setup 


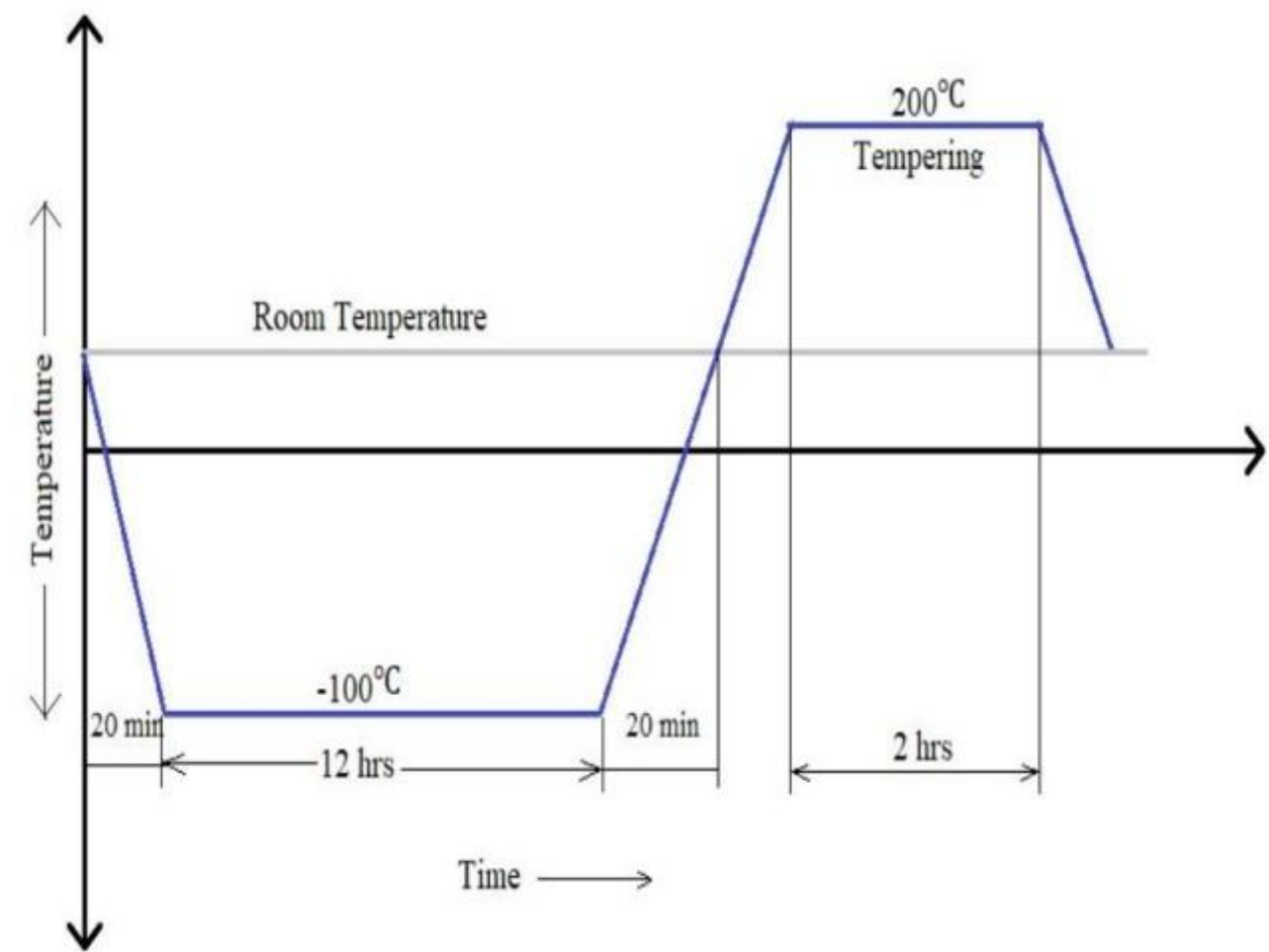

Fig. 2. Heat treatment of a tool insert 


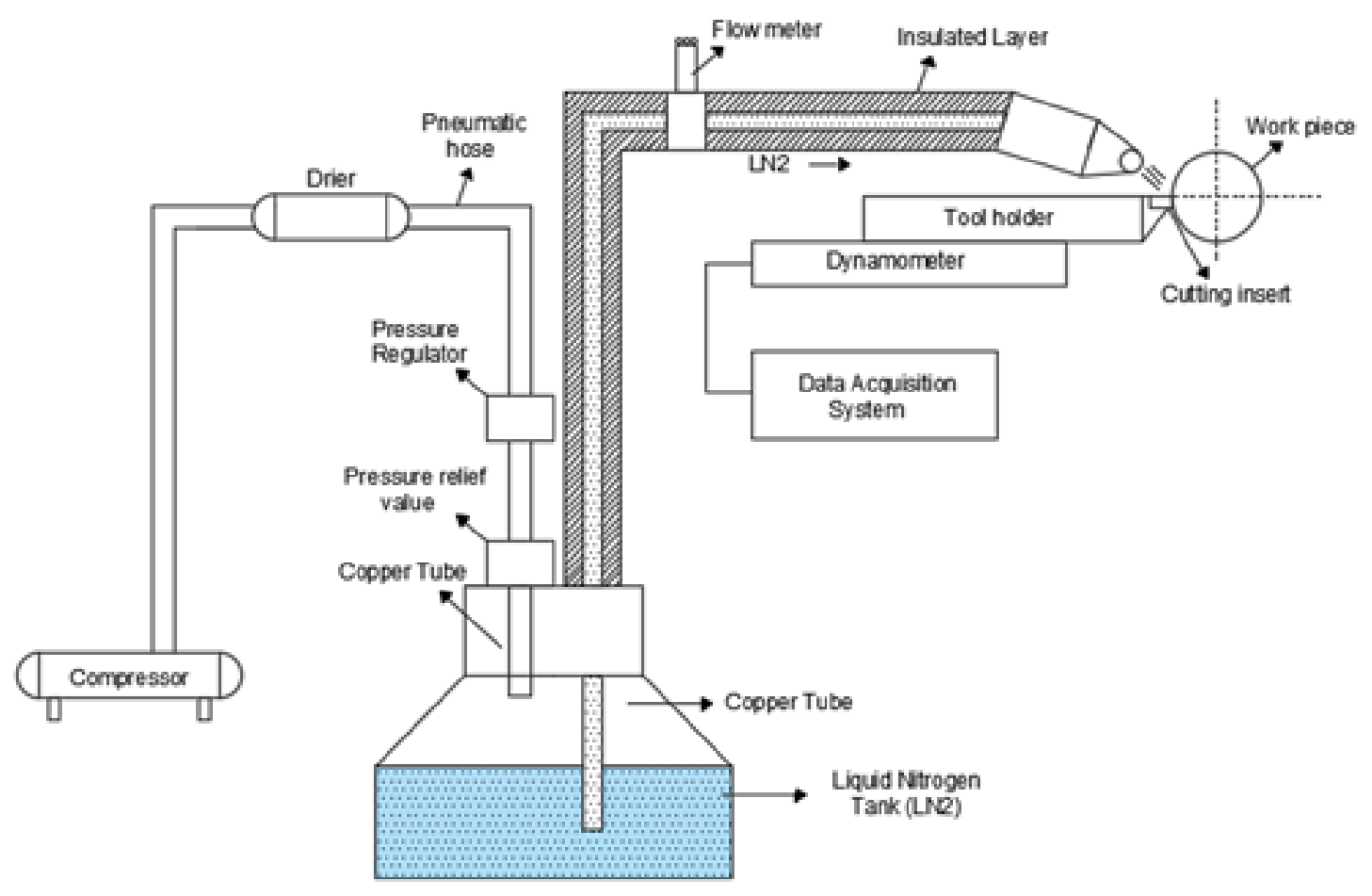

Fig. 3. Schematic of cryogenic liquid nitrogen machining setup 

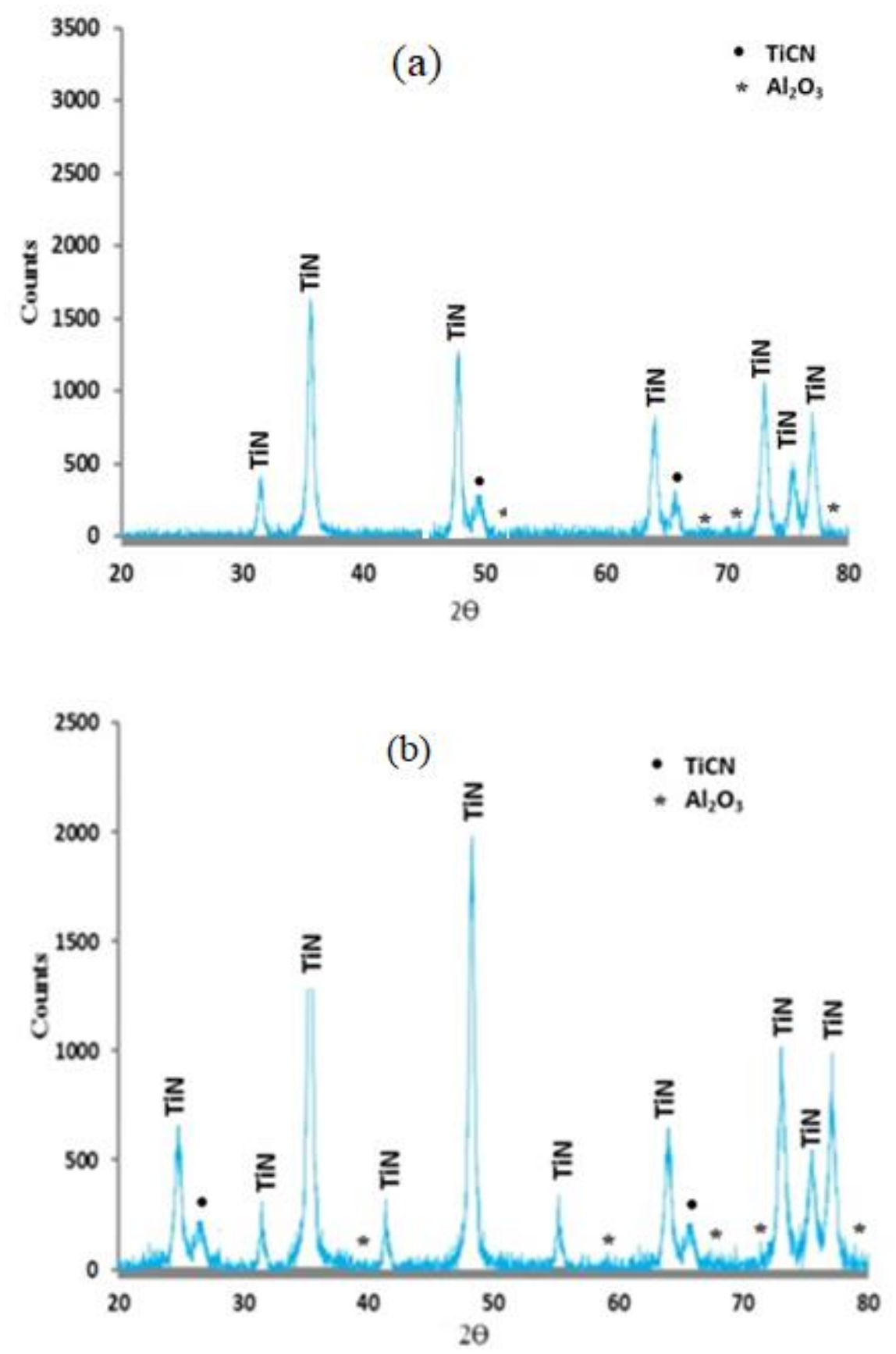

Fig. 4. XRD pattern for the (a) untreated tool and (b) treated tool insert 


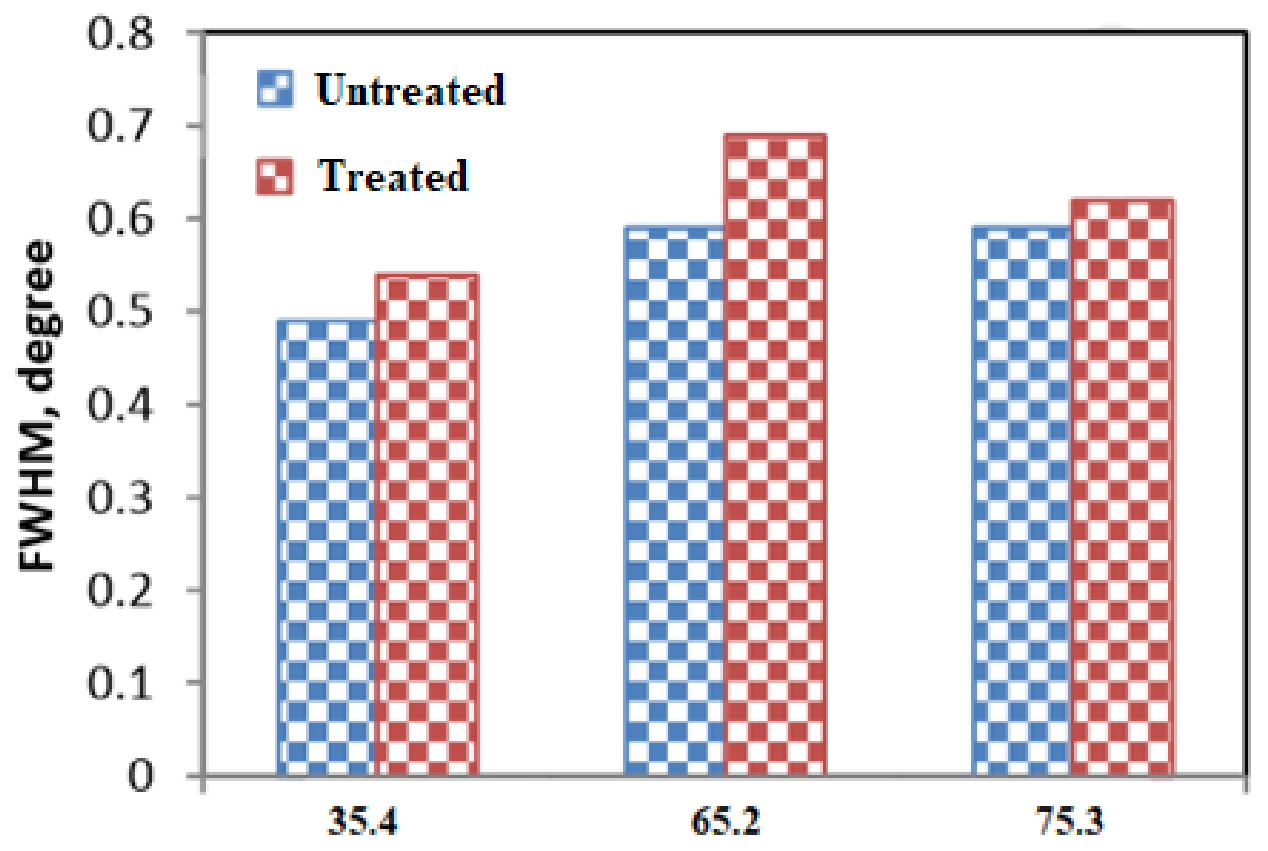

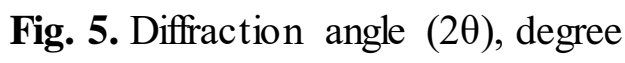




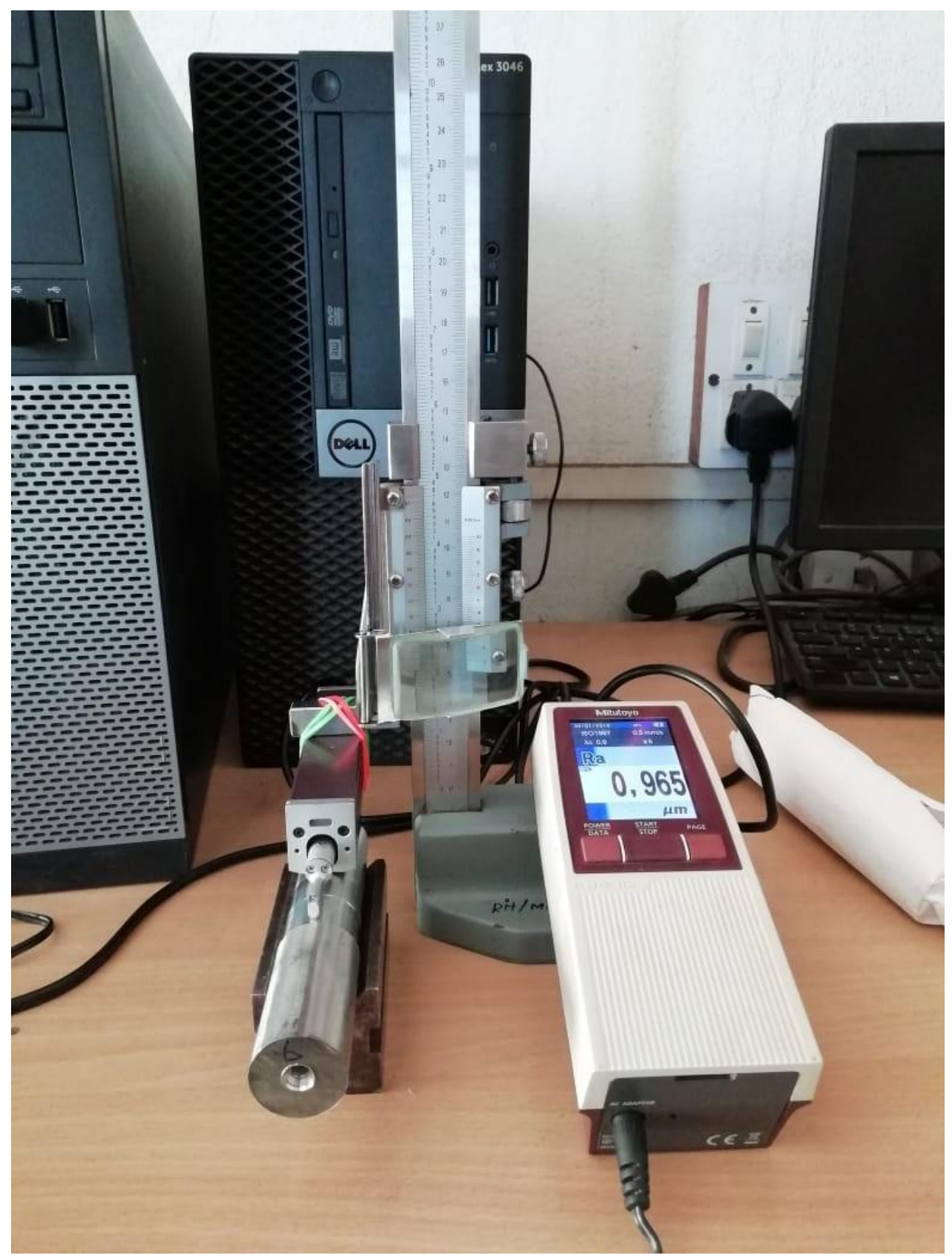

Fig. 6. Surface roughness tester used for a measurement of surface roughness 


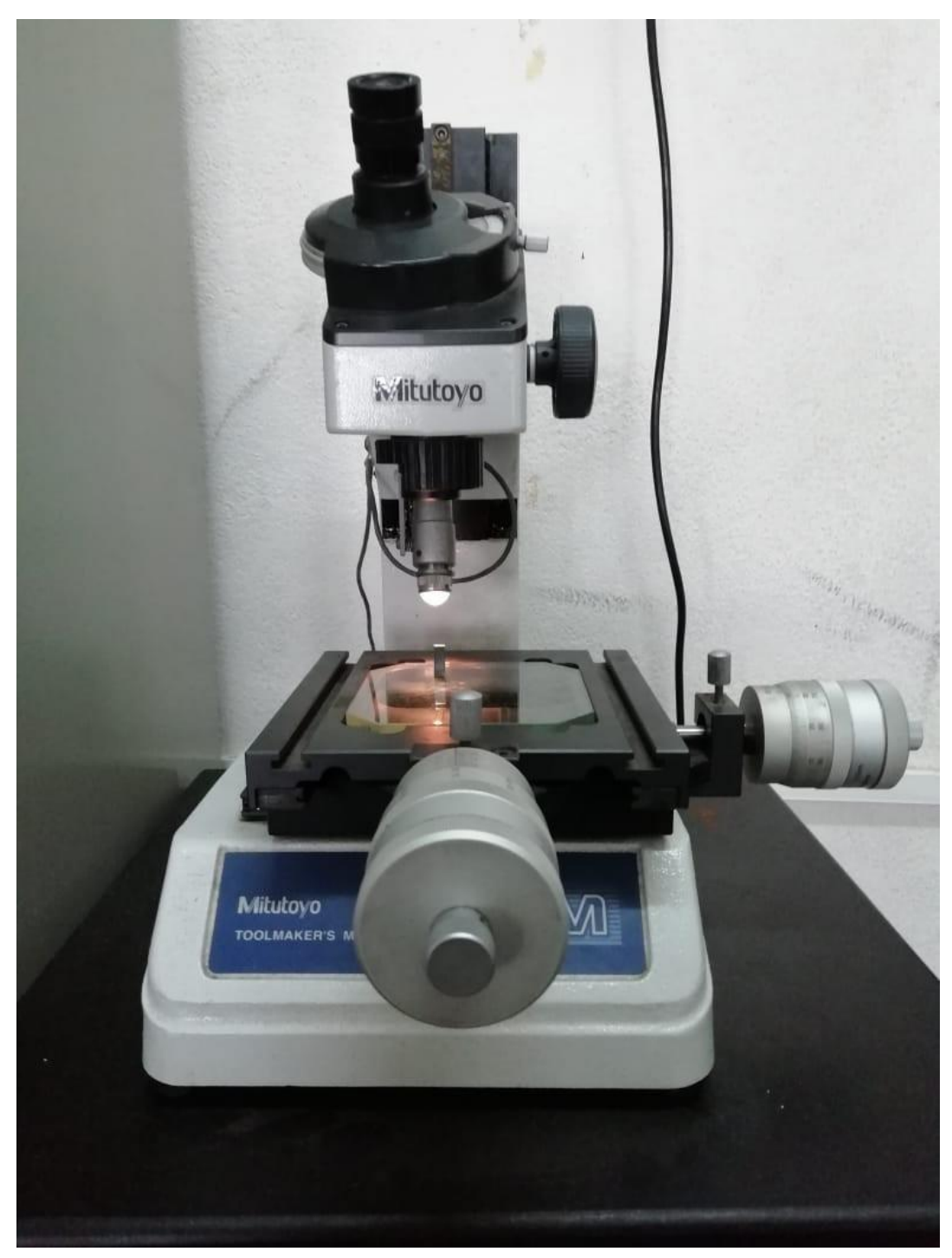

Fig. 7. Tool makers' microscope used for a measurement of nose wear 


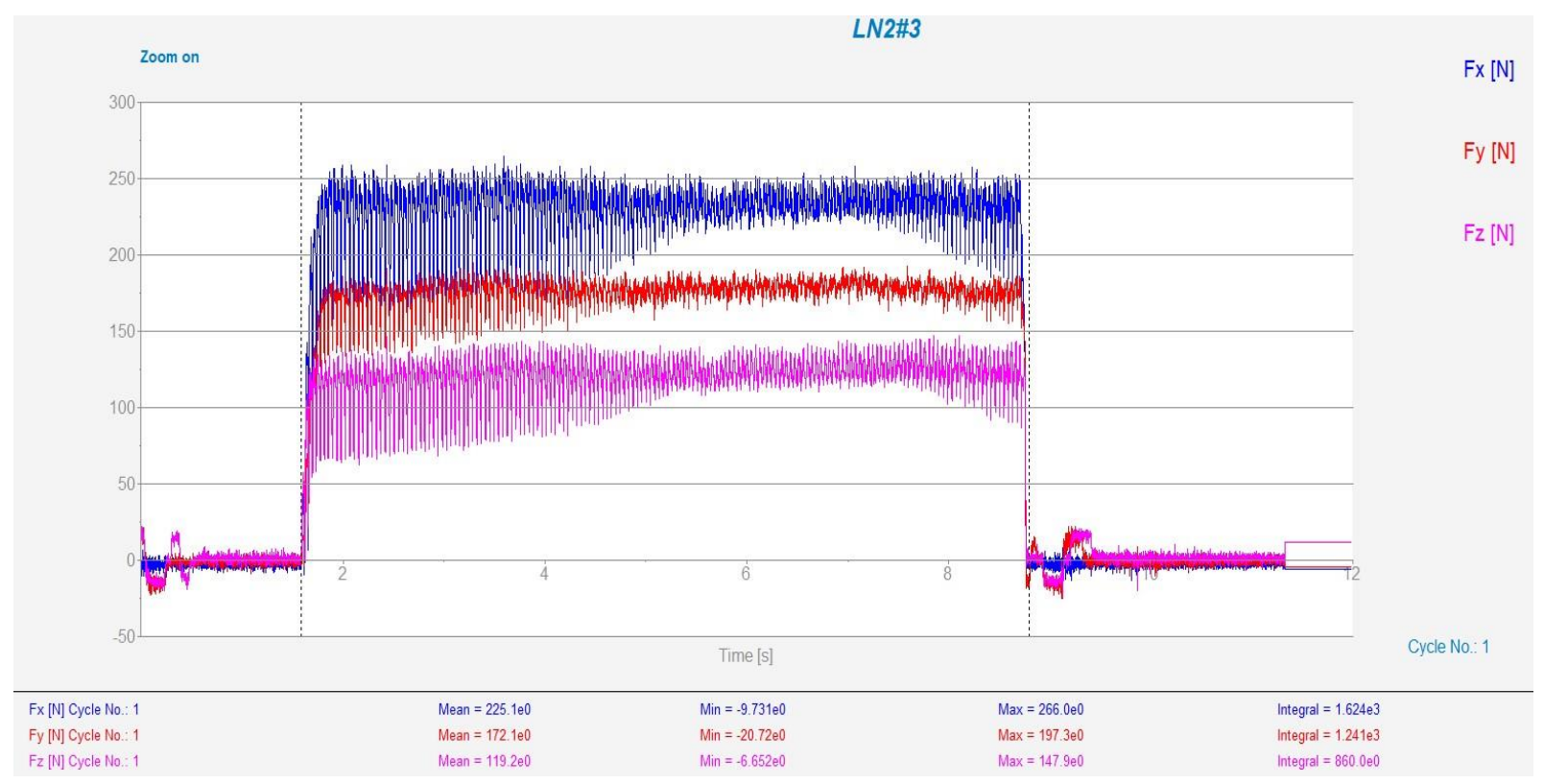

Fig. 8. Data acquisition system of DynoWare software for cutting forces 


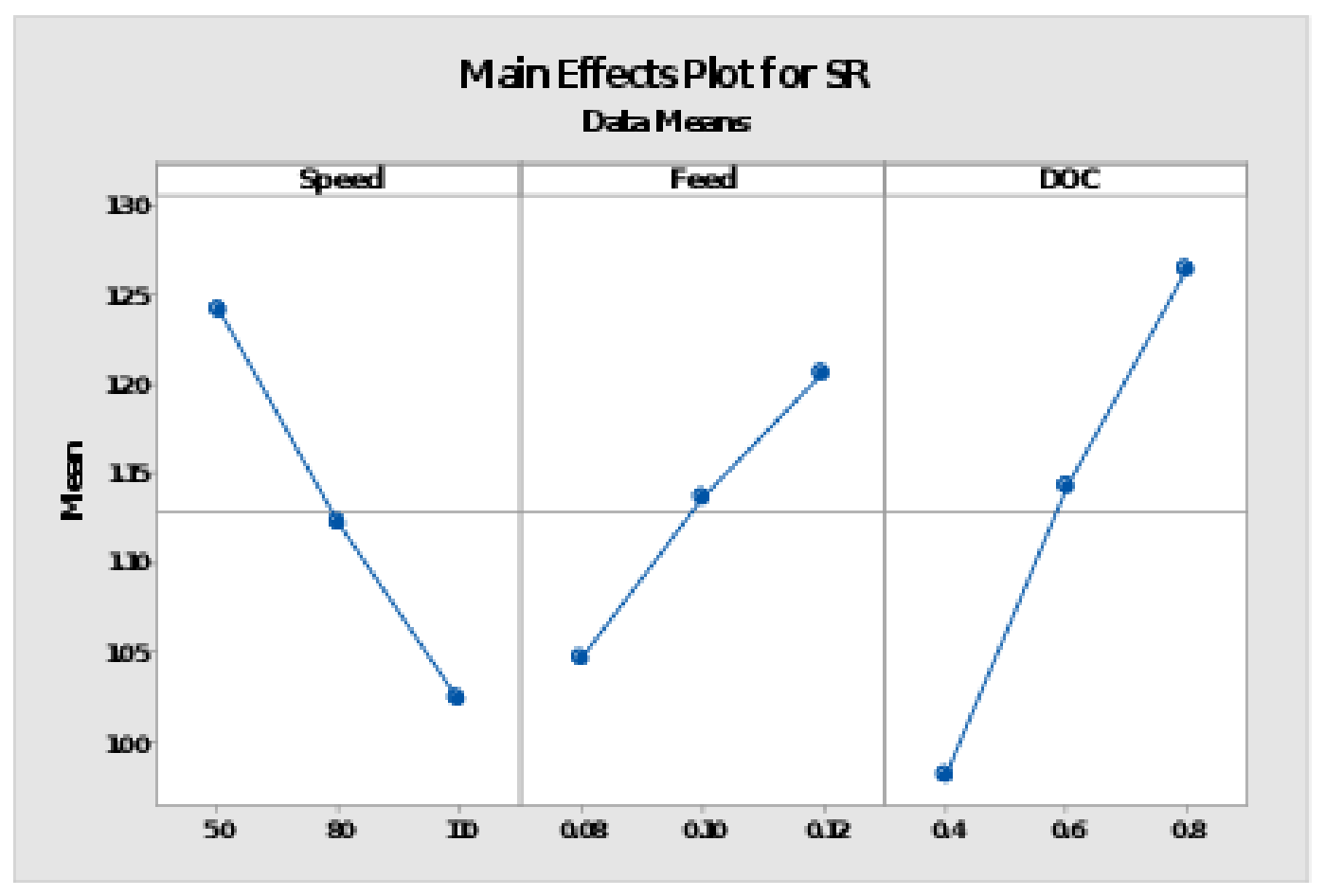

Fig. 9. Main effect plot for surface roughness 


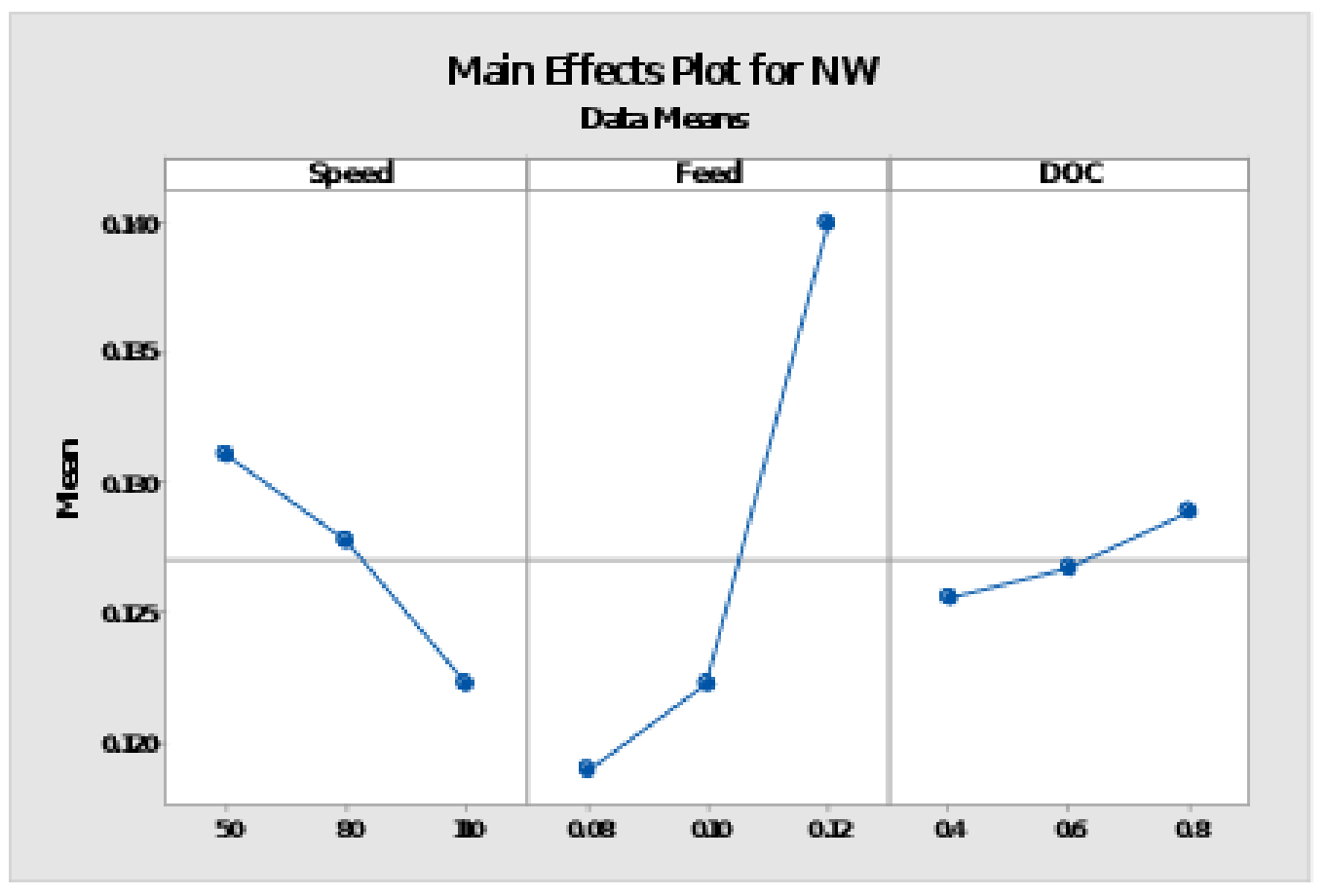

Fig. 10. Main effect plot for nose wear 


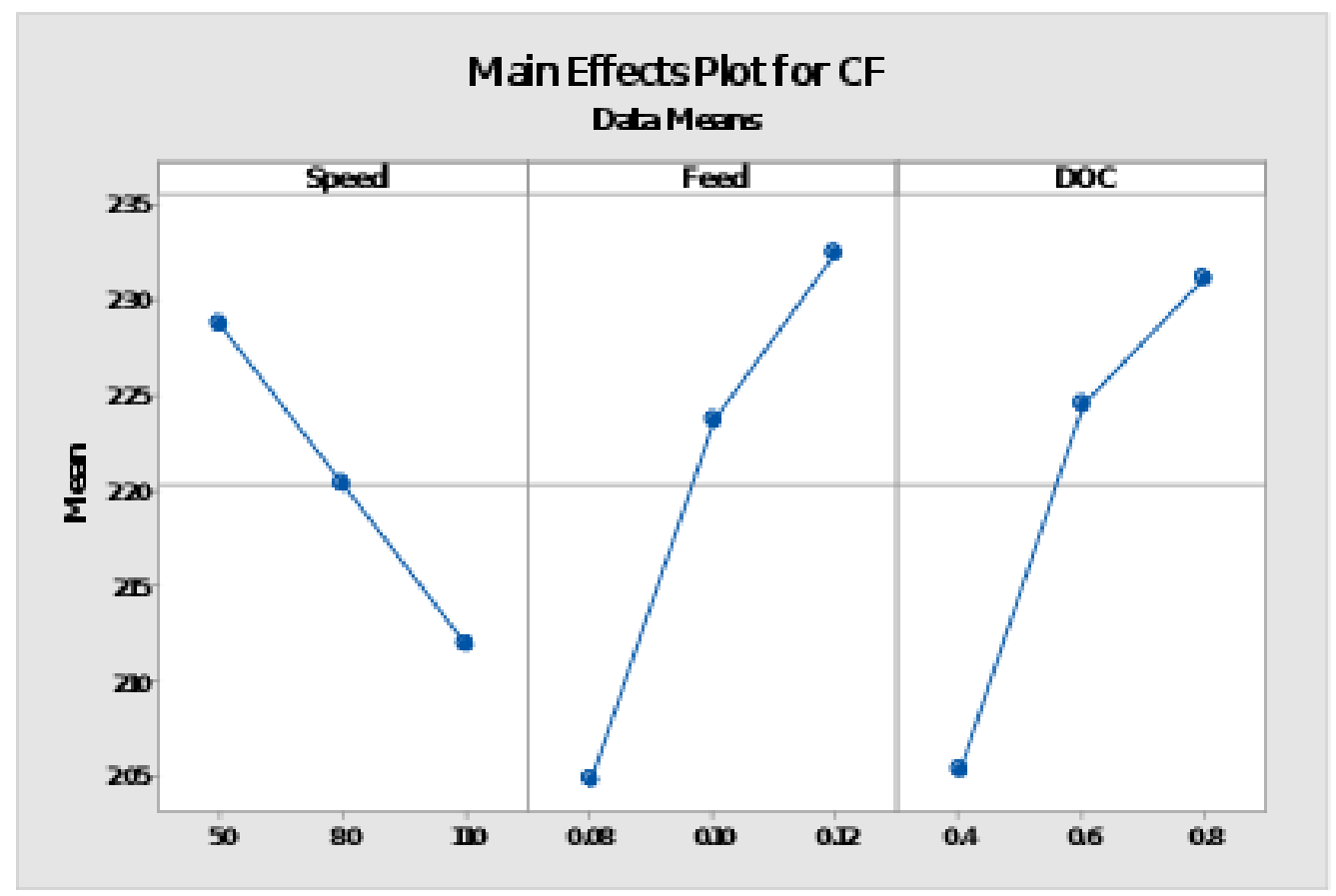

Fig.11. Main effect plot for cutting forces 

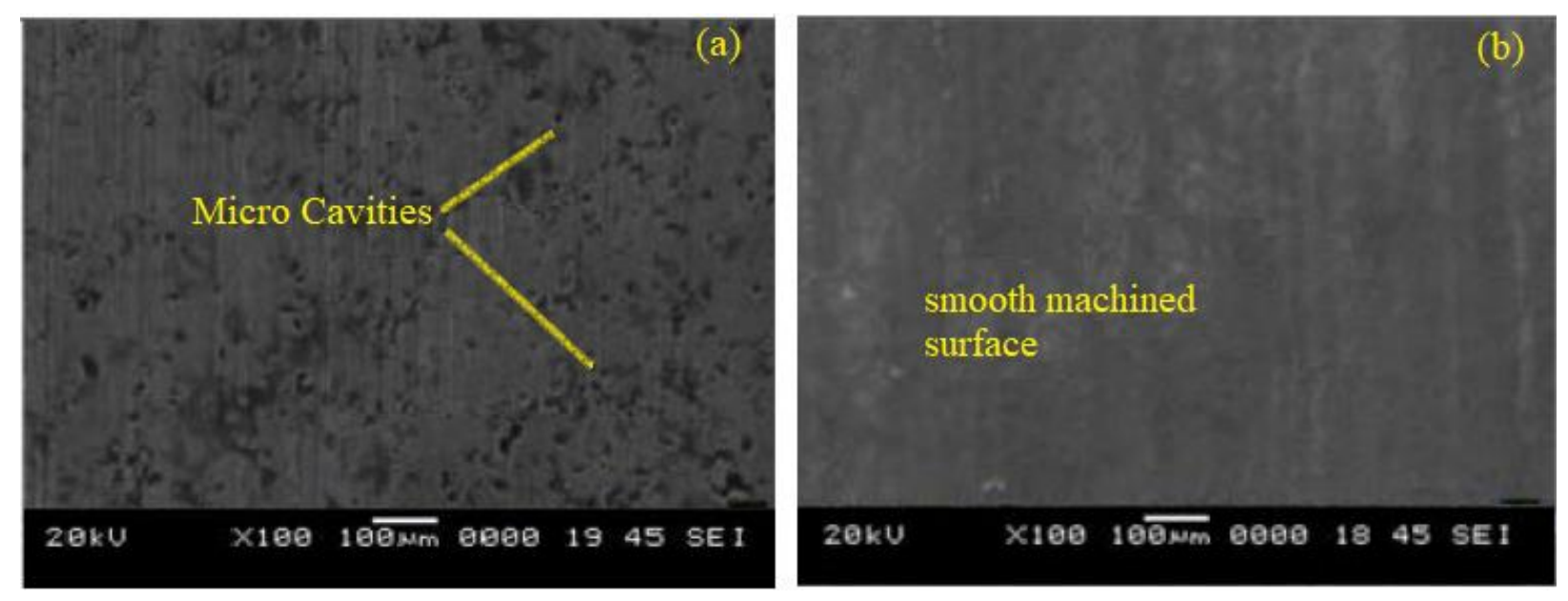

Fig. 12. SEM morphology of machined surface

(a) $2^{\text {nd }}$ orthogonal array $\left(\mathrm{N}_{1} \mathrm{~F}_{1} \mathrm{D}_{1}\right)(\mathrm{b})$ optimum machining condition based on TGRA $\left(\mathrm{N}_{3} \mathrm{~F}_{1} \mathrm{D}_{1}\right)$ 

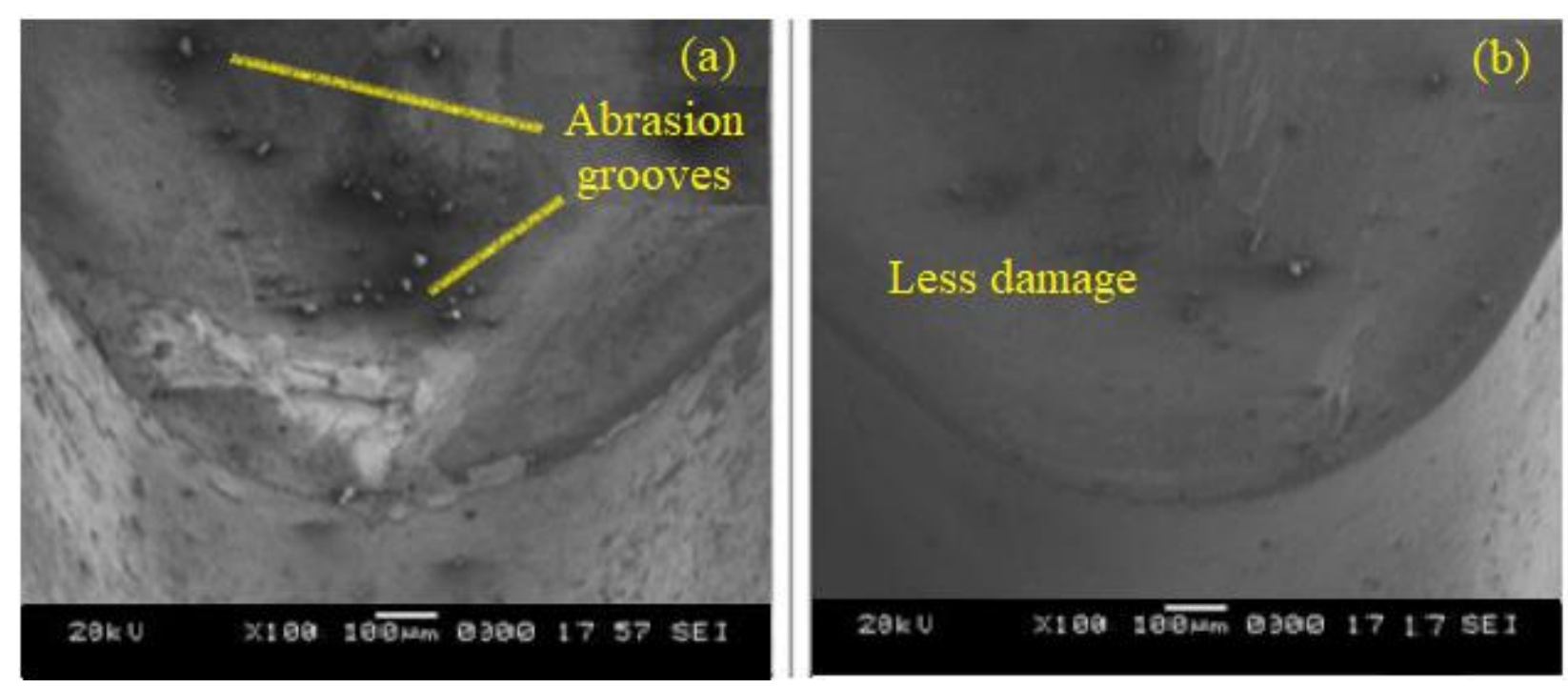

Fig. 13. SEM morphology of cutting tool

(a) $2^{\text {nd }}$ orthogonal array $\left(\mathrm{N}_{1} \mathrm{~F}_{1} \mathrm{D}_{1}\right)$ (b) optimum machining condition based on TGRA $\left(\mathrm{N}_{3} \mathrm{~F}_{1} \mathrm{D}_{1}\right)$ 


\section{List of Tables}

Table 1. Mechanical properties of Nimonic C-263, Podder and Paul (2012)

\begin{tabular}{ccccc}
\hline Material & $\begin{array}{c}\text { Yield strength } \\
(\mathbf{M P a})\end{array}$ & $\begin{array}{c}\text { Hardness } \\
(\mathbf{H V})\end{array}$ & $\begin{array}{c}\text { Tensile strength } \\
(\mathbf{M P a})\end{array}$ & $\begin{array}{c}\text { Tensile strength } \\
(\mathbf{M P a})\end{array}$ \\
\hline Nimonic C-263 & 400 & 300 & 540 & 540 \\
\hline
\end{tabular}


Table 2. Experimental Details

\begin{tabular}{|l|l|}
\hline Work piece & Nimonic C-263 alloy \\
Composition (\%) & C- 0.06, Al- 0.33, Co- 19.89, Cr- 20.41, Fe- 0.45, Mo- \\
Machine & 5.85, Ti- 2.11, N- 0.006 (Balanced Ni) \\
MTAB Max Turn plus CNC Machine \\
Cutting Insert & Kennametal (TNMG160408MP KCM25) \\
Input Parameters (3 levels) & L-27 (Taguchi's approach) \\
& Cutting speed (50,80,110m/min), \\
& Cutting Feed (0.08,0.1,0.12 mm/rev), \\
Performance Measures & cutting forces, surface roughness and nose wear \\
\hline
\end{tabular}


Table 3. Results of turning operation along with Grey relational coefficients (GRC), Grey relational grade (GRG) and rank

\begin{tabular}{|c|c|c|c|c|c|c|c|c|c|c|c|}
\hline \multirow{2}{*}{ Sr. No. } & \multirow{2}{*}{$\begin{array}{r}\text { Speed, } \mathbf{N} \\
(\mathrm{m} / \mathrm{min})\end{array}$} & \multirow{2}{*}{$\begin{array}{c}\text { Feed, F } \\
(\mathrm{mm} / \mathrm{rev})\end{array}$} & \multirow{2}{*}{$\begin{array}{c}\text { DOC,D } \\
(\mathbf{m m})\end{array}$} & \multirow{2}{*}{$\begin{array}{c}\mathbf{S R} \\
(\mu \mathrm{m})\end{array}$} & \multirow{2}{*}{$\begin{array}{c}\text { NW } \\
(\mathbf{m m})\end{array}$} & \multirow{2}{*}{$\begin{array}{l}\mathbf{C F} \\
(\mathbf{N})\end{array}$} & \multicolumn{3}{|c|}{ Grey Relational Coefficient } & \multirow{2}{*}{$\begin{array}{c}\text { Grey } \\
\text { Relational } \\
\text { Grade }\end{array}$} & \multirow[b]{2}{*}{ Ranl } \\
\hline & & & & & & & SR GRC & NW GRC & CFGRC & & \\
\hline 1 & 50 & 0.08 & 0.4 & 0.723 & 0.21 & 203.4 & 0.8379 & 0.5 & 0.76228 & 0.700059 & 15 \\
\hline 2 & 50 & 0.08 & 0.4 & 0.911 & 0.07 & 188.3 & 0.7582 & 1 & 0.816239 & 0.858153 & 1 \\
\hline 3 & 50 & 0.08 & 0.4 & 1.017 & 0.09 & 192.36 & 0.7196 & 0.875 & 0.800994 & 0.798543 & 6 \\
\hline 4 & 50 & 0.1 & 0.6 & 1.345 & 0.12 & 174.5 & 0.6217 & 0.7368 & 0.872694 & 0.743757 & 14 \\
\hline 5 & 50 & 0.1 & 0.6 & 1.581 & 0.14 & 315.3 & 0.5663 & 0.6667 & 0.511636 & 0.581535 & 26 \\
\hline 6 & 50 & 0.1 & 0.6 & 0.815 & 0.12 & 218.99 & 0.7969 & 0.7368 & 0.713577 & 0.749112 & 13 \\
\hline 7 & 50 & 0.12 & 0.8 & 1.111 & 0.21 & 258.53 & 0.6886 & 0.5 & 0.614072 & 0.600878 & 25 \\
\hline 8 & 50 & 0.12 & 0.8 & 1.812 & 0.13 & 214.6 & 0.5208 & 0.7 & 0.726651 & 0.649166 & 22 \\
\hline 9 & 50 & 0.12 & 0.8 & 1.858 & 0.09 & 292.6 & 0.5127 & 0.875 & 0.548202 & 0.645285 & 23 \\
\hline 10 & 80 & 0.08 & 0.6 & 1.052 & 0.11 & 261.73 & 0.7077 & 0.7778 & 0.607219 & 0.69758 & 17 \\
\hline 11 & 80 & 0.08 & 0.6 & 1.715 & 0.16 & 174.5 & 0.539 & 0.6087 & 0.872694 & 0.673468 & 20 \\
\hline 12 & 80 & 0.08 & 0.6 & 0.821 & 0.08 & 201.99 & 0.7944 & 0.9333 & 0.767015 & 0.831577 & 3 \\
\hline 13 & 80 & 0.1 & 0.8 & 0.881 & 0.1 & 323.22 & 0.7699 & 0.8235 & 0.5 & 0.697811 & 16 \\
\hline 14 & 80 & 0.1 & 0.8 & 0.612 & 0.13 & 198.7 & 0.8933 & 0.7 & 0.778294 & 0.79054 & 9 \\
\hline 15 & 80 & 0.1 & 0.8 & 1.922 & 0.15 & 171.22 & 0.5017 & 0.6364 & 0.887281 & 0.675106 & 19 \\
\hline 16 & 80 & 0.12 & 0.4 & 1.332 & 0.12 & 149.1 & 0.6251 & 0.7368 & 1 & 0.787315 & 10 \\
\hline 17 & 80 & 0.12 & 0.4 & 1.112 & 0.14 & 312.2 & 0.6882 & 0.6667 & 0.516339 & 0.623751 & 24 \\
\hline 18 & 80 & 0.12 & 0.4 & 0.662 & 0.16 & 190.8 & 0.8675 & 0.6087 & 0.806783 & 0.760985 & 12 \\
\hline 19 & 110 & 0.08 & 0.8 & 0.433 & 0.14 & 196.55 & 1 & 0.6667 & 0.785846 & 0.817504 & 5 \\
\hline 20 & 110 & 0.08 & 0.8 & 0.812 & 0.13 & 172.3 & 0.7982 & 0.7 & 0.882424 & 0.793538 & 7 \\
\hline 21 & 110 & 0.08 & 0.8 & 1.932 & 0.08 & 252.43 & 0.5 & 0.9333 & 0.627573 & 0.686969 & 18 \\
\hline 22 & 110 & 0.1 & 0.4 & 1.112 & 0.14 & 255.72 & 0.6882 & 0.6667 & 0.620218 & 0.658377 & 21 \\
\hline 23 & 110 & 0.1 & 0.4 & 0.998 & 0.1 & 186.5 & 0.7263 & 0.8235 & 0.823185 & 0.790991 & 8 \\
\hline 24 & 110 & 0.1 & 0.4 & 0.967 & 0.1 & 169.61 & 0.7373 & 0.8235 & 0.894621 & 0.818495 & 4 \\
\hline 25 & 110 & 0.12 & 0.6 & 1.432 & 0.2 & 292.4 & 0.6001 & 0.5185 & 0.548548 & 0.555715 & 27 \\
\hline 26 & 110 & 0.12 & 0.6 & 0.631 & 0.12 & 218.4 & 0.8833 & 0.7368 & 0.715307 & 0.778491 & 11 \\
\hline 27 & 110 & 0.12 & 0.6 & 0.899 & 0.09 & 163.07 & 0.7628 & 0.875 & 0.925727 & 0.854526 & 2 \\
\hline
\end{tabular}


Table 4. Response table for GRG

\begin{tabular}{ccccccc}
\hline \multirow{2}{*}{ Symbol } & $\begin{array}{c}\text { Process } \\
\text { parame ters }\end{array}$ & \multicolumn{5}{c}{ Grey relational grade } \\
\cline { 3 - 7 } & Level 1 & Level 2 & Level 3 & Delta & Rank \\
\hline $\mathrm{N}$ & $\begin{array}{c}\text { Cutting speed } \\
(\mathrm{m} / \mathrm{min})\end{array}$ & 0.7029 & 0.7264 & $\mathbf{0 . 7 5 0 5}$ & 0.0476 & 3 \\
$\mathrm{~F}$ & $\begin{array}{c}\text { Cutting feed } \\
(\mathrm{mm} / \mathrm{rev})\end{array}$ & $\mathbf{0 . 7 6 1 9}$ & 0.7228 & 0.6951 & 0.0668 & 1 \\
$\mathrm{D}$ & $\begin{array}{c}\text { Depth of cut } \\
(\mathrm{mm})\end{array}$ & $\mathbf{0 . 7 5 5 1}$ & 0.7184 & 0.7063 & 0.0488 & 2 \\
\hline
\end{tabular}


Table 5. ANOVA for GRG

\begin{tabular}{ccccc}
\hline Source & DF & Adj SS & Adj MS & \% contribution \\
\hline Speed & 2 & 0.013322 & 0.006661 & 14.90 \\
Feed & 2 & 0.043214 & 0.021607 & 48.33 \\
Depth of cut & 2 & 0.032876 & 0.016438 & 36.77 \\
Total & 6 & 0.089412 & & \\
\hline
\end{tabular}


Table 6. Results of turning operations in confirmation test

\begin{tabular}{lccc}
\hline & $\begin{array}{c}\text { Orthogonal } \\
\text { trial No 2 }\end{array}$ & Optimal machining parameters using \\
\cline { 3 - 4 } & & Predicted & Experimental \\
\cline { 2 - 4 } & $\mathrm{N}_{1} \mathrm{~F}_{1} \mathrm{D}_{1}$ & $\mathrm{~N}_{3} \mathrm{~F}_{1} \mathrm{D}_{1}$ & $\mathrm{~N}_{3} \mathrm{~F}_{1} \mathrm{D}_{1}$ \\
Level & 0.911 & & 0.837 \\
Surface Roughness $(\mu \mathrm{m})$ & 0.07 & 0.06 \\
Nose wear $(\mathrm{mm})$ & 188.3 & 161.14 \\
Cutting forces $(\mathrm{N})$ & 0.8581 & 0.8992 & 0.9383 \\
Grey relational grade $(\mathrm{GRG})$ & & \\
The improvement in GRG= 0.0802 & & & \\
The percentage improvement in GRG $\mathbf{9 9 . 3 4 \%}$ & & \\
\hline
\end{tabular}

